\title{
PRESCRIPCIONES
}

\section{Túa Blesa}

Universidad de Zaragoza

Todo texto aspira a ser él mismo, es decir, a ser él mismo sin dejar abierta ninguna posibilidad a la confusión con cualquiera de los otros, lo que le lleva necesariamente a participar en un debate sobre la identidad. Sobre su propia identidad en cuanto garantía de ser tal texto y no cualquiera de los otros, de alcanzar la diferencia $-\mathrm{y}$ habrá que decir que semejante garantía actúa también como horizonte, lo que quiere decir que tanto se avanza hacia él, como se imagina, o reedifica, en otro lugar más allá-. Ahora bien, este ímpetu por alcanzar la diferencia, la que hará posible su propia identidad, no puede llevar, en su hacerse, a un texto tan lejos de todos los otros como para perderse de vista, como para que tal texto no fuese ya reconocible como elemento de la textualidad, perdidos sus vínculos, su aire de familia, con ésta o aquella serie, como para no llegar a ser página del libro único - pretendiéndose literario, del volumen que acoge la textualidad literaria-, de manera que su necesaria diferencia de todos los otros textos habrá de compaginarse con el mantenimiento de tal(es) o cual(es) rasgo(s) compartido(s) con éstos, con la identidad con todos ellos o, al 
menos, con algunos. Debate, pues, sin fin, el de todo texto, abierto a una serie ilimitada de soluciones, debate por el cual un texto se afirma y se niega, al mismo tiempo que afirma y niega a todos los restantes; en cualquier caso, los repite, ya sea por la reiteración efectiva de alguno de sus componentes, ya sea por haberlos instituido como punto de partida, desde el cual emprende su fuga, aunque lleva impresa su marca en forma de diferencia. Y, en cuanto tal, también este texto es partícipe de semejante debate.

Es de ahí de donde surge una gran parte de la escritura - será mejor decir que toda ella - teórica. Por supuesto, toda aquélla que establece semejanzas entre unas obras y otras, la que delimita tipos textuales - de hecho, esto es lo que es, claro que entre otras cosas, el tratado Sobre la Poética de Aristóteles-, o bien se fundamenta sobre los ya señalados, pero también aquélla otra que simplemente rebate todo ello. Es esta última la posición del pensamiento de, por ejemplo, Benedetto Croce -quien ve tan sólo en la obra su singularidad, aquello que la constituye como idéntica a sí misma y a la intuición de la que es no otra cosa que su expresión, ella misma, como se lee en su conocida Estética- o, más modernamente, de Maurice Blanchot, quien en El libro que vendrá supo ver, y expresar, cómo la obra no pertenece a tal o cual género, sino que ésta atraviesa todos los tipos y circunscripciones literarias, pero las atraviesa para salir de tales pasos inmaculada, como si fuese indiferente a sus exigencias, sorda a sus preceptos, sin reparar en sus limitaciones, de tal modo que, escribe Blanchot, «cualquier libro concierne únicamente a la literatura» (1979: 25), relación única y directa sin intermediario alguno.

Es el caso, pues, que el señalamiento de rasgos unificadores y la consiguiente elaboración de tipologías han venido atendiendo a los más variopintos componentes de la textualidad, lo que ha conducido a una situación en la cual muchas de las tipologías de los textos literarios que usualmente se manejan - $\mathrm{y}$, desde luego, el conjunto de ellas, si se pudiesen proyectar las unas sobre las otras y observar semejante totalidad - no merecen mayor crítica que el decir que recuerdan - y yo mismo no me excluyo, pues en mi Logofagias. Los trazos del silencio he tenido que escribir que un mismo texto es, a un tiempo, un ejemplo, pongamos, de adnotatio y óstracon, etc. (véase Blesa, 1998) - , recuerdan, digo, aquella clasificación de cierta enciclopedia china, cuyo título reclama ser reproducido, Emporio celestial de conocimientos benévolos, citada por Jorge Luis Borges en su «El idioma analítico de John Wilkins». Se lee allí que en tal enciclopedia, 
está escrito que los animales se dividen en (a) pertenecientes al Emperador, (b) embalsamados, (c) amaestrados, (d) lechones, (e) sirenas, (f) fabulosos, (g) perros sueltos, (h) incluidos en esta clasificación, (i) que se agitan como locos, (j) innumerables, (h) dibujados con un pincel finísimo de pelo de camello, (1) etcétera, (m) que acaban de romper el jarrón, (n) que de lejos parecen moscas (Borges, 1960: 142).

$\mathrm{Y}$ es que la multiplicidad de criterios - que responden, por una parte, a presupuestos teóricos de lo más diverso, como es lógico, y a la complejidad de formantes de los textos, por otra-, como sucede en el caso de los redactores del citado Emporio, hace que los espacios tipológicos descritos no encajen a modo de un rompecabezas, sino que se superponen de tal modo que el resultado acaba siendo desesperanzador por dibujar un sistema tan asistemático que es la imagen misma de lo caótico.

Pese a ello, se persiste en la mirada de Linneo, la cual, al enfocar la variabilidad indefinida de las obras, no cesa de percibir rasgos y toda clase de componentes comunes a éste y aquel texto, similitudes sobre las que se asientan las múltiples tipologías hasta hoy propuestas, sustentadas en principios de la más varia naturaleza.

Parece, sin embargo, que los tipos métricos son de otra especie, pues están bien establecidos, por cuanto sus reglas son precisas, normalmente claras, basadas en la presencia, en un segmento de discurso, de acentos, determinado número de sílabas, identidades fónicas, etc., es decir, se trata de características mensurables con escaso, por no decir nulo, margen de error por cuanto sus unidades son discretas. Pero sucede que la práctica literaria, en no pocas ocasiones al menos, está en continua pugna con las reglas establecidas, como si hubiese hecho suya, elevada a uno de los principios rectores de su dicción, la contradicción. Así, siendo que la distinción verso/prosa admite pocas dudas, se presenta como conflictiva cuando se atiende, por ejemplo, al siguiente poema de Stéphane Mallarmé, del que a continuación copio su título y algunas líneas de su comienzo:

\section{PROSE \\ pour des Esseintes}

Hyperbole! De ma mémoire Triomphalement en sais-tu

Te lever, aujourd'hui grimoire

Dans un livre de fer vêtu:

Car j'installe, par la science,

L'hymne des coeurs spirituels. 
En l'oeuvre de ma patience, Atlas, herbiers et rituels.

[...]

(Mallarmé, 1992: 55-6)

Es suficiente este fragmento para mostrar cómo las expectativas, escasas, por lo demás, si bien claras, que el título había hecho vislumbrar se arruinan en cuanto se accede al texto, que no es, pese a «Prose», prosa, sino, precisamente, lo contrario, verso, la negación pura y simple de aquélla, de manera que esta página mallarmeana es, por el nombre, lo uno y, por su disposición rítmica, lo otro: texto en verso cuyo nombre es prosa.

Un caso semejante lo ofrece este poema de Leopoldo María Panero, incluido en su El que no ve, del que también copio tan sólo un fragmento de su comienzo:

\author{
NECRIFILIA (prosa) \\ El acto del amor es lo más parecido \\ a un asesinato. \\ En la cama, en su terror gozoso, se trata de borrar \\ el alma del que está, hombre o mujer, \\ debajo. \\ $[\ldots]$
}

(Panero, 1980: 15)

De nuevo, el nombre del poema en verso es «prosa». Copresencia de lo opuesto, de las dos grandes formas de composición textual, que se diría remite a la idea de Samuel Taylor Coleridge expuesta en su Biographia Literaria, donde, preguntándose qué sea la poesía, resuelve contestar a qué sea el poeta, lo que le lleva a situar en el lugar de la definición a la imaginación, es decir,

This power, first put in action by the will and understanding and retained under their irremissive, though gentle and unnoticed, controul (laxis effertur habenis) reveals itself in the balance or reconciliation of opposite or discordant qualities: of sameness, with difference; of the general, with the concrete; the idea, with the image; the individual, with representative; the sense of novelty and freshness, with old and familiar objects [...] (Coleridge, 1980: 174; estas últimas cursivas son mías).

Ante ejemplos como éste convendrá decir que el texto sobreviene como el lugar de la violencia $\mathrm{o}$, al menos, del roce de lo distinto, de lo 
divergente, que ha de conciliarse una vez que ha sido convocado en el texto y presentado hecho todo uno en el acto de lectura. Así, la literatura es aquel espacio de la palabra en el que conviven, como si dijésemos, en armonía, al menos en ocasiones, la ley y su infracción, siendo por otra parte, como es, obvio que la infracción no podría llegar a darse sin la presencia misma de la ley, que en literatura adopta, por lo menos en la edad moderna (aunque al menos ocasionalmente siempre ha sido así), ya no la forma del precepto inviolable, sino la del uso, de la tradición, a modo de su imagen dulcificada y más fácilmente susceptible de transgresión. A esto mismo se refería Blanchot en el citado El libro que vendrá cuando escribía que «la excepción nos revela esa "ley" cuya insólita y necesaria desviación la constituye ella también» (1979: 125).

Más delicado es el caso en que la caracterización tipológica no implica tan sólo la organización rítmica, sino que atañe además a rasgos estilísticos e incluso temáticos. Así, entre las cantigas de la lírica gallegoportuguesa se distinguen las «de maestría», que carecen de estribillo y tratan preferentemente de amor, y las «de refram», que sí incluyen estribillo y que se usan en las cantigas de amigo y también de escarnio (obsérvese que se dice «preferentemente»), o la endecha, que, si se caracteriza por su asunto luctuoso, los tratadistas no dejan de señalar que el verso de que se sirven es usualmente breve, o, en fin, es común que el villancico se ocupe de tema religioso y el estribote lo es tanto por su carácter burlesco, cuanto por su estructura de zéjel octosilábico. Y, para poner otros ejemplos, considérese el limerick, escritura del sinsentido, por una parte, y de organización sintagmática y versal bien fijada, por otra, o el haiku, de caracterización también múltiple. Por supuesto, todos estos tipos de estructuras imponen sus peculiares reglas y restricciones compositivas en un cierto momento, las mantienen durante un tiempo más o menos largo, pero se podría decir que tales normas están destinadas siempre a la relajación y que ninguna de ellas carece de alguna disposición derogatoria, como si la caducidad les fuese inherente.

Siendo así, las caracterizaciones de los tipos textuales y sus designaciones son únicamente elementos a la espera de su utilización recta o violentada. Esto último es lo que sucede en el siguiente poema de Antonio Martínez Sarrión de Horizonte desde la rada, en el que, por lo demás, el título es toda una advertencia:

\section{HAI-KU CON TODA LICENCIA}

Con gracia cabecea la embarcación

en el centro geométrico de mi punto de mira: 
sale de foco, resta su canción.

Enamorado el mar, hondo respira.

(Martínez Sarrión, 1983: 49)

Siendo que el haiku, además de otras determinaciones, tiene una serie de reglas compositivas que son de naturaleza métrica, por las cuales un haiku consta de tres versos de cinco, siete y cinco sílabas respectivamente, tal como sucede en los textos tradicionales japoneses (literatura cuya versificación es de naturaleza silábica, como es bien sabido), el poema de Martínez Sarrión excede tanto el número de versos canónicos, cuanto la extensión silábica de cada uno de ellos y además incluye la rima (ausente en sus modelos), por lo que este haiku es, siendo que el título lo nombra así, un haiku, aunque, también de acuerdo con el título, lo es «con toda licencia». Y añadiré que no se violan únicamente las reglas versificatorias, sino también aquéllas que atañen al estilo, como la economía de medios, etc. Claro que habría que añadir que el haiku desde su implantación en la literatura hispánica, desde sus verdaderos inicios en la obra de José Juan Tablada, ya experimentó algunas innovaciones con respecto a la tradición japonesa. Así, los seminales poemas de Un día... (1919) de Tablada, si bien mantienen la práctica totalidad de ellos la composición en tres versos, presentan una notable libertad en la medida de éstos e introducen sistemáticamente la rima de los versos impares y van todos ellos dotados de título, con lo que inauguraban en este nuevo ámbito literario un tipo poético que se desvinculaba de algunos de sus modos japoneses, de manera que el haiku hispano comenzó desde sus textos fundacionales siendo haiku con toda licencia, de lo que el poema citado parece levantar acta ${ }^{1}$.

Según esta tradición hispana, de incorporación con adaptación, en la práctica poética se vienen denominando haikus textos que ni de lejos recuerdan a las muestras de Matsuo Bashó y del resto de haikistas japoneses, sino que, aunque dicho sea de manera muy imprecisa, tan sólo se atienen a una cierta brevedad, tal como sucede con la mayoría de los que exhiben tal título en la obra del poeta español contemporáneo que con mayor frecuencia presenta este tipo de poemas en sus

${ }^{1}$ De hecho, Un día... se subtitula Poemas sintéticos y no utiliza los términos haiku o hai-kai, si bien la filiación es indudable desde el poema-dedicatoria inicial (en el que se nombra al mismísimo Bashó). No deja de anotar este hecho Héctor Valdés en el prólogo a su edición de las poesías de Tablada, donde escribe que el citado libro es «no de hai-kái, sino de "poemas sintéticos": los llamó así seguramente porque las dimensiones de sus poemas no se ajustaban a la forma clásica del haikú» (Tablada, 1991: 18). 
libros, Leopoldo María Panero, a propósito de los cuales advertí en otra ocasión, en Leopoldo María Panero, el último poeta, que «son tales únicamente por cuanto así se indica en los títulos o subtítulos y por ser poemas breves» (Blesa, 1995: 30), lo que, sin embargo, tampoco cumple, como se verá, el que transcribo ahora, tomado de Narciso en el acorde último de las flautas:

\title{
LE BON PASTEUR
}

(Haikú)

\begin{abstract}
Es duro el trabajo de la pesadilla, es duro arrastrar día el carro de las marionetas, de noche; y ser una de ellas mañana, cuando abran los ojos para no ver que la bailarina de cuerda danzando entre ellas mueve ella misma el resorte.
\end{abstract}

(Panero, 1979: 96) $^{2}$

Si sobre el poema antes transcrito ha habido que decir que los límites métricos del haiku habían sido desbordados, ahora hay que repetir lo mismo, sólo que, como suele decirse, corregido y aumentado, en armonía, por cierto, con la poética del exceso en la que se inscribe la escritura de Leopoldo María Panero. Y para lo que aquí importa lo destacable es que se sigue conservando el marbete de haiku para titular, designar, textos que poco o directamente nada tienen que ver con las características de tal tipo poético, al tiempo que, en otras ocasiones, sirve para nombrar poemas que sí entran dentro de los límites de tal poética y no sólo en los aspectos métricos. Así, por ejemplo, los reunidos por Vicente Huici en Teoría del extraño movimiento (25 haiku), de los que copio el que abre la colección:

\author{
entre las ruinas \\ la túnica de Ulises \\ y sus sandalias
}

(Huici, 1985: 11).

2 Como el lector habrá observado, «arrastrar día el carro de las marionetas» incluye una errata, que se repite en la recopilación de la obra poética de Panero Poesía 1970-1985 (1986: 163), y cuya lectura probable es «arrastrar de día». 
Además de que el número de versos y las sílabas de éstos son los canónicos, ha de anotarse el estilo nominal, el no transcurso del tiempo, ese puro presente tan tópico del haiku, la referencia al paisaje, el sugerir más que el decir, como rasgos haikistas (aunque el lector habrá notado la falta del «kigo», de la palabra de estación, como sucede, por lo demás, en no pocos de los textos japoneses modernos), lo que, sin embargo, se combina aquí con elementos característicamente típicos de la tradición occidental en un texto híbrido que no renuncia a ninguna de las tradiciones, sino que da como resultado una plena fusión. Así, «haiku» es término de una significación de lo más inestable: si en unas ocasiones se corresponde con toda una serie de dispositivos rítmicos, estilísticos y de contenido - digámoslo así-, es decir, continúa una composición tradicional, en otras es una indicación que no se refleja en ninguno de los componentes del poema, como si de una denominación vacía se tratase, si bien, habrá de decirse que también en estos casos se perpetúa una tradición, sólo que de un modo singular.

No es el citado el único tipo poético que presenta paradojas y, como veremos, no menos significativas que las puestas en evidencia por los haikus y, en realidad, por todos los tipos textuales. Así, la sección II de «Jeunesse» de Arthur Rimbaud en Illuminations lleva el título de «Sonnet», cuando es sin más poema en prosa, tal como muestra este fragmento:

Homme de constitution ordinarie, la chair n'était-elle pas un fruit pendu dans le verger, $-\hat{o}$ journées enfantes! le corps un trésor à prodiguer; $-\hat{o}$ aimer, le péril ou la force de Psyché? La terre avait des versants fertiles en princes et en artistes, et la descendance et la race vous poussaient aux crimes et aux deuils: le monde votre fortune et votre péril (Rimbaud, 1972: 147).

Y también bajo el mismo epígrafe la forma esquiva la organización típica, ahora no como prosa, sino en verso, aunque ni presenta los catorce canónicos, ni siquiera se somete al isosilabismo, etc., este poema de La rosa firme de Koldo Artieda:

\section{SONETO}

Impulso lunar

de un corazón abierto

arde

estallar

en azulados

oscuros claros

blanquísimos

(Artieda, 1982: 34). 
En realidad, cualquier comentario se me antoja absolutamente superfluo, de manera que paso a atender otro caso.

He mencionado antes, como ejemplo de estrofa que responde a reglas métricas y también a otras —cual es la repetición de ciertos elementos en algunos de sus versos-, el limerick. El siguiente texto de Teoría de Leopoldo María Panero incumple unas y otras, aunque, por supuesto, la mención del tipo poético al que pertenece no falta:

\section{LSD limerick}

Alicia en el llano sonaba
con rojo teji·ó su baba
un viejo en la cruz·ágata
en lámpara viejo ojo y cruz
esquizofrénico niño mas
un viejo que en el yano hablaba.

(Panero, 1973: 72) ${ }^{3}$

Es verdad que la versificación de este tipo textual responde a los principios de la poesía en lengua inglesa (cinco versos, de los que los 1,2 y 5 son trímetros y los 3 y 4 dímetros, con rima $a a b b a$ ) y que, por tanto, alguno de ellos requeriría cierta adaptación al escribir en español (en cuanto a lo ya indicado, el lector puede hacer el análisis para comprobar las violaciones), pero el típico paralelismo de los versos inicial y final, que era fácilmente reproducible, tampoco se ha mantenido, aunque sí se trata de un limerick en cuanto expresión del disparate. Sólo queda añadir que Panero conocía bien las características de este tipo poético, pues el año anterior a la publicación de Teoría había aparecido su traducción, bajo el título de El ómnibus, sin sentido (Lear, 1972), de un conjunto de limericks de Edward Lear ${ }^{4}$.

Me referiré ahora al poema en prosa, que quedó caracterizado por Charles Baudelaire, en el prólogo a sus Petits poëmes en prose (Le spleen de Paris), como «une prose poétique, musicale sans rhythme et sans rime» (1973: 22). Así, el poema en prosa quedaba instituido como un texto poético caracterizado negativamente en cuanto que implicaba la renuncia a los recursos que tradicionalmente habían venido configurando al poema. A partir de entonces, la noción de

3 Tengo en cuenta las correcciones de la edición en Poesía 1970-1985 (1986: 106).

4 Sobre los trabajos de traducción de Panero, que él prefiere llamar perversión, véase mi Leopoldo María Panero, el último poeta (Blesa, 1995: 79-89). 
poema se ha ampliado, tanto que se desliga de la idea misma de verso y los elementos que, repetidos, lo constituyen. Ahora el poema, el poema en prosa, simplemente no tiene ya versos («sans rhythme»), ni tampoco rima («sans rime»). Se clausuraban aquí las imposiciones que la oralidad había imprimido sobre el discurso poético. En la era de la literatura escrita, tal requisito era ya superfluo, una excrecencia de otro universo literario (como el verso libre confirma), una deuda con la tradición - pero, siendo la tradición otra, la de la literatura oral, la deuda era gratuita-, universo que, por lo demás, pervive, pues los universos literarios no se sustituyen, sino que más bien se superponen en relación de convivencia y tanto es así que, siendo el poema en prosa el tipo poético más característico, junto a la novela, de la literatura escrita (la literatura doblegada finalmente a su étimo, a la letra), no ha relegado al olvido las estructuras estróficas tradicionales, ni tan siquiera es ni con mucho el más frecuente - y creo que cabe añadir que, en términos generales, tampoco el más prestigioso- en la producción literaria de la etapa contemporánea $y$, en consecuencia, muy escasamente atendido en los estudios literarios. Parece como que el peso de la tradición ejerce su presión mucho más allá de las condiciones que impusieron unas determinadas formas y las explican y, así, los cambios ocurren siempre fuera de su tiempo, inevitablemente a destiempo.

Sin embargo, el desarrollo del poema en prosa ofrece muestras que suponen un absoluto desvío de las reglas negativas que enunció Baudelaire. Y no se trata ahora de que otras estructuras lingüísticas de repetición (anáfora, etc.) doten de ritmo al discurso poético —como sucedía ya en no pocos de los textos de Baudelaire (véase Le poème en prose, de Suzanne Bernard, 1994: 136-45)—, sino de dar la espalda a los preceptos fundacionales para producir un extraño y paradójico, otra vez, texto. Sea este poema de Mandorla de José Ángel Valente:

\section{ESPACIO}

El espacio que sólo se divide en gérmenes de gérmenes de gérmenes. El tiempo que empieza apenas a durar. El movimiento que está ya consumado en esta mano inmóvil y tendida al arqueado lomo del animal en el que tiene forma, no fraguada aún la forma, la caricia. La longitud enorme del camino que la mano habrá de recorrer hasta alcanzar el punto en donde, posada ya en el tacto, aguarda la mirada. No media el tiempo sino la interminable duración del deseo entre la palma y el suave descenso de tu vientre. Antecesión o sucesión. Yo estoy llegando a ti y aún no toco tu borde, en el que ya se abrasa la memoria.

(Valente, 1982: 17) 
Como el lector habrá observado, este poema en prosa - de que se trata de tal cosa no puede haber ningún género de duda - resulta en la lectura plenamente rítmico. Y es que todo el discurso de «Espacio» - título que, por otra parte, impone rememorar el gran poema de Juan Ramón Jiménez, una de las mayores muestras de este tipo textual y uno de los mayores poemas contemporáneos- está metrificado en secuencias rítmicas endecasilábicas y, dicho brevemente, otras de clave impar, es decir, las formas versificatorias más características de la poesía en verso de José Ángel Valente, de manera que, en lo que al ritmo se refiere, en la lectura, en la audición, no hay diferencia sustancial -excepción sea hecha de las pausas- entre sus poemas en verso y este «Espacio» y varios otros más de sus poemas en prosa, que se identifican como tales tan sólo por su disposición gráfica. Pero esto no es poco, pues cada una de estas disposiciones inscribe al texto de que se trate en una determinada estela de tradición poemática y, en la lectura, se está reclamando tal perspectiva (independientemente, o no, de que temas, estilos, etc. abran sus propias líneas de lectura).

Pero es el caso que Baudelaire había escrito que el poema en prosa era, según hemos visto, «une prose poétique, musicale sans rhythme et sans rime». Sin embargo, este «Espacio»-y muchos otros poemas en prosa y muchos más todavía si se considera tan sólo alguno de sus pasajes- es una prosa poética, musical sin rima («sans rime») y sin verso («sans rhythme»; «comprenons du rhythme des vers», señala Suzanne Bernard, 1994: 129; la cursiva es suya), y, pese a ello, con ritmo. Si bien renuncia a la imposición rítmica básica de la oralidad, al verso, este tipo de poema en prosa la recupera en una forma disfrazada, fundiendo el ritmo del discurso y la representación prosaica. Como tipo literario de la modernidad, el poema en prosa sólo pudo concebirse en cuanto negación, pero esa capacidad negativa no se consumió en su formación, sino que, grabándose en él como si le perteneciera para siempre - se diría que como destino-, continúa en él en ejemplos como el citado, textos que se revuelven contra su propia definición, mostrando de este modo que su esencia es la violación de la norma, y hasta tal punto es así que se alcanza la transgresión de su propia norma transgresora (en su momento; aunque también, al menos en parte, hoy por la mencionada escasez), sin dejar por ello de ser, con toda legitimidad, poema en prosa ${ }^{5}$.

${ }^{5}$ La metrificación del discurso no se da únicamente, por supuesto, en el poema en prosa. Francisco Umbral, por ejemplo, somete ocasionalmente el lenguaje de su columna periodística a períodos rítmicos. 
El siguiente ejemplo, uno de los textos que componen Baladas del Dulce Jim de Ana María Moix — conjunto de poemas en prosa, alguno de los cuales, por otra parte, es híbrido por cuanto incluye algún fragmento en verso-, lleva un poco más allá este quehacer de deshacer:

[XV]

Ay madre, ya soy como la España; ni chicha ni limoná, loquita del corazón y dura como la caña.

(Moix, 1983: 32)

En efecto, este brevísimo poema en prosa no sólo adopta la dicción metrificada, sino que además incorpora una cierta rima, con lo que supone la negación de las negaciones que Baudelaire había proclamado, de manera que el poema de Ana María Moix representa algo así como el poema en prosa anti-poema en prosa.

Los ejemplos anteriores, y muchos otros textos equivalentes, permiten atisbar con cierta claridad cuál es el valor moderno, por lo menos, que las estructuras estróficas o, si se prefiere, los tipos poéticos definidos por su disposición rítmica, y también de otras naturalezas, tienen. Si en clave clásica — mucho mejor que decir en época — «soneto» designa una combinación bien fijada y lo mismo, mutatis mutandis, cabe decir de «haiku», «limerick», etc., o de la disposición gráfica en el caso de un poema en prosa, en clave moderna la situación es muy otra: tales términos, y la disposición gráfica advertida, se han abierto hasta alcanzar una profunda ambigüedad, de modo que, si, en algunos casos, continúan remitiendo a una organización tradicional, repetida, en otros, tal función se ha anulado. No por ello la aparición de tales indicaciones tipológicas en los textos es superflua, sino que lo que se ha producido es una revalorización, de manera que «haiku» en el título de un poema que no cumple ninguna de sus reglas compositivas puede adquirir una tonalidad irónica o hacer manifiesta, sin más, la paradoja, tal como también ocurre, creo que en grado máximo, con la disposición gráfica en el poema de Ana María Moix citado. En cualquier caso, sucede que semejantes señales continúan remitiendo a una tradición - abriendo así uno de los caminos de lectura posibles o uno que es necesario-, al par que la muestran violentada. Con ello las oposiciones soneto/no-soneto, etc., se diluyen, pues un texto puede ser tanto soneto, por su denominación, cuanto nosoneto si se atiende al número de sus versos, y otro es poema en prosa, por la forma en que se representa en la página, $y$, sin embargo, su prosa es tan rítmica como si fuese verso y además hasta alguno de sus seg- 
mentos riman. En definitiva, los textos «incluidos en esta clasificación», para decirlo con expresión del Emporio celestial de conocimientos benévolos, en cualquiera de ellas, han llevado a cabo una neutralización de las diferencias que los identifican - lo que se extiende a todos los valores que conlleven los tipos, valores que son inherentes a toda distinción $\mathrm{y}$, por supuesto, arbitrarios- y difieren esas diferencias a un momento que está siempre por llegar, diferidas al país de nunca jamás.

Desde allí llega la reconstrucción de un tipo de texto que deja atrás la oposición, por ejemplo, haiku/no-haiku, el sistema, por cuanto hay algún poema que es tanto lo uno como lo otro, las dos cosas a un tiempo y, sobre todo, algo más que todo eso. Y habrá que conceder a estas prácticas de escritura el que llevan a cabo la deconstrucción de todo un sistema, no sólo el del caso específico que representan, sino, en último término, el de toda tipología textual y la posibilidad misma de establecerla. Por otra parte, los textos aquí citados y todos aquellos que cumplen esta desestabilización del sistema literario - - o, dicho de otro modo, la sustitución de un sistema por otro- serían de verdad los auténticamente literarios si se acepta la idea de Maurice Blanchot, leída en su ya citado El libro que vendrá, según la cual «la esencia de la literatura consiste en escapar a toda determinación esencial, a toda afirmación que la estabilice o realice» (Blanchot, 1979: 225), textos que además hacen exhibición de esa fuga al consignar el nombre de la determinación a la que escapan.

Nos enseñan, por último - ya se entiende que en esta lectura y no como conclusión definitiva, pues en este sentido estas páginas sólo deben leerse como el comienzo de un trazado aún por recorrer--, nos enseñan, digo, que el ser un texto ejemplo de un determinado tipo es el resultado de haberse sometido a un conjunto de prescripciones sobre cómo han de organizarse algunos de sus elementos compositivos, pero también que tales prescripciones contienen en sí mismas su propia cláusula de prescripción, si bien de un modo según el cual su prescripción no impide, más allá de ella, la inscripción de sus prescripciones en la escritura.

Prescribir: decretar y caducar. A la vez.

\section{Referencias bibliográficas}

ARTIEDA, Koldo (1982). La rosa firme. Madrid: Trieste.

Baudelaire, Charles (1973). Petits poëmes en prose (Le spleen de Paris), Robert Kopp (ed.). París: Gallimard. 
BERnARD, Suzanne (1994). Le poème en prose. De Baudelaire jusqu'à nos jours. París: Nizet (1. ${ }^{\mathrm{a}}$ ed. 1959).

Blanchot, Maurice (1979). El libro que vendrá. Pierre de Place (trad.). Caracas: Monte Ávila.

BlesA, Túa (1995). Leopoldo María Panero, el último poeta. Madrid: Valdemar.

- (1998). Logofagias. Los trazos del silencio. Zaragoza: «Trópica». Anexos de Tropelías.

BORGES, Jorge Luis (1960). «El idioma analítico de John Wilkins». En Otras inquisiciones, 139-144. Buenos Aires: Emecé.

COLERIDGE, Samuel Taylor (1980). Biographia Literaria. George Watson (ed. e intr.). Londres: Dent \& Sons.

HuICI, Vicente (1985). Teoría del extraño movimiento (25 haiku). Pamplona: Pamiela.

LEAR, Edward (1972). El ómnibus, sin sentido. Leopoldo María Panero (selec., trad. y pról.). Madrid: Visor.

Mallarmé, Stéphane (1992). Oeuvres complètes. Henri Modor y G. JeanAntony (eds.). París: Gallimard.

MARTÍnez SARRIón, Antonio (1983). Horizonte desde la rada. Madrid: Trieste.

MoIX, Ana María (1983). Baladas del Dulce Jim (1969). En A imagen y semejanza. Barcelona: Lumen.

PANERo, Leopoldo María (1979). Narciso en el acorde último de las flautas. Madrid: Visor.

- (1980). El que no ve. Madrid: La Banda de Moebius.

- (1986). Poesía 1970-1985. Madrid: Visor.

Rimbaud, Arthur (1972). Oeuvres complètes. Antoine Adam (ed.). París: Gallimard.

Tablada, José Juan (1991). Obras. I. Poesía. Héctor Valdés (recopilación, ed., pról. y nn.). México: UNAM (1. ${ }^{\mathrm{a}}$ ed. 1971).

VALENTE, José Ángel (1982). Mandorla. Madrid: Cátedra. 